\title{
Building on good data foundations
}

\author{
Theodora Bloom executive editor
}

The BMJ

"Healthcare generates a vast rainforest of data that could be used more widely for research if barriers to access could be overcome," say Ruth Gilbert and colleagues in an Editorial (doi:10.1136/bmj.h5897). The barriers include the cost of access and cumbersome application processes. And where are the incentives to provide data for research? Could we quantify the lost opportunities of research not done and do more to encourage data providers to list who has accessed their data and to what end?

Large scale imaging studies are now recruiting hundreds of thousands of volunteers, and we can expect thousands of incidental findings to crop up, say J M Wardlaw and colleagues in their Analysis article (doi:10.1136/bmj.h5190). We need to agree who should do what with these data and how to explain their potential use to the participants. What are the ethical, pragmatic, and proportionate ways of dealing with incidental findings of uncertain clinical significance?

The potentially rich pickings from large scale data are evident in two research papers this week describing the development and validation of risk scores. Samira Bell and colleagues (doi:10. $1136 / \mathrm{bmj} . \mathrm{h} 5639$ ) look at the risk of acute kidney injury in orthopaedic surgery patients. They built a model using data from 6200 patients in two hospitals in Scotland and validated it in 4400 patients from a third. Julia Hippisley-Cox and Carol Coupland (doi:10.1136/bmj.h5441), by contrast, used large scale English general practice data to build a risk prediction model for blindness and lower limb amputation in diabetics. Their model building cohort included 455000 patients, and results were validated with a further 206000 . As noted in the accompanying editorial (doi:10.1136/bmj.h5643), we now need to know whether the results of this large scale model lead to practice changes that do improve the management of people with diabetes and reduce rates of blindness and amputation.

Data access and reuse surface elsewhere this week. In an investigation conducted jointly with the Times, Gareth Iacobucci (doi:10.1136/bmj.h6000) describes the £2.4bn (€3.4bn; \$3.6bn) in contracts that have been awarded by clinical commissioning groups in England to organisations in which their board members have a financial interest. Though the groups do operate within the rules on conflicts of interest, it doesn't look good, particularly given such wide variation in how the rules are applied. You may sympathise with the GP who says, "Try to trust that there are some of us out here trying to do the right thing for patients," or with the chair of the BMA's General Practitioners Committee, who says instead that GPs who are directors of provider organisations should simply not hold a board position on any group that could commission services from that provider.

Finally, Margaret McCartney (doi:10.1136/bmj.h5995) says that if England's health secretary wants to be viewed as a colleague, he should be less gung ho with the data when he draws conclusions about a seven day NHS. Perhaps, as letter writer Kevin Newman suggests (doi:10.1136/bmj.h5986), it is time for Hunt to get together with the authors of a contested paper in The BMJ on weekend mortality (doi:10.1136/bmj. h4596; doi:10.1136/bmj.h5624) to agree what its data show.

Cite this as: BMJ 2015;351:h6065

๑ BMJ Publishing Group Ltd 2015 